\title{
Meta-Analysis of Artificial Intelligence Works in Ubiquitous Learning Environments and Technologies
}

\author{
Caitlin Sam ${ }^{1}$, Nalindren Naicker ${ }^{2}$, Mogiveny Rajkoomar ${ }^{3}$ \\ Department of Information Systems \\ Durban University of Technology \\ Durban, KwaZulu-Natal
}

\begin{abstract}
Ubiquitous learning (u-learning) refers to anytime and anywhere learning. U-learning has progressed to be considered a conventional teaching and learning approach in schools and is adopted to continue with the school curriculum when learners cannot attend schools for face-to-face lessons. Computer Science, namely the field of Artificial Intelligence (AI) presents tools and techniques to support the growth of u-learning and provide recommendations and insights to academic practitioners and AI researchers. Aim: The aim of this study was to conduct a meta-analysis of Artificial Intelligence works in ubiquitous learning environments and technologies to present state from the plethora of research. Method: The mining of related articles was devised according to the technique of Preferred Reporting Items for Systematic Reviews and MetaAnalyses (PRISMA). The complement of included research articles was sourced from the broadly used databases, namely, Science Direct, Springer Link, Semantic Scholar, Academia, and IEEE. Results: A total of 16 scientific research publications were shortlisted for this study from 330 articles identified through database searching. Using random-effects model, the estimated pooled estimate of artificial intelligence works in ubiquitous learning environments and technologies reported was $10 \%(95 \%$ CI: $\left.3 \%, 22 \% ; I^{2}=99.46 \%, P=0.00\right)$ which indicates the presence of considerable heterogeneity. Conclusion: It can be concluded based on the experimental results from the sub group analysis that machine learning studies [18\% (95\% CI: $11 \%$, $\left.25 \%), I^{2}=99.83 \%\right]$ was considerably more heterogeneous $\left(I^{2}=\right.$ $99.83 \%$ ) than intelligent decision support systems, intelligent systems and educational data mining. However, this does not mean that intelligent decision support systems, intelligent systems and educational data mining is not efficient.
\end{abstract}

Keywords-Educational data mining; intelligent systems; artificial intelligence; PRISMA; machine learning; ubiquitous learning

\section{INTRODUCTION}

Ubiquitous learning (u-learning) is a shift from the elearning paradigm which describes an environment that permits the use of ubiquitous computing devices to access teaching and learning contents by means of wireless networks at any time and in any location. U-learning is characterized by accessibility where the information is readily available whenever learners need its utilization. In u-learning the information remains on the platform and is always available to learners. There is immediacy where the information can be acquired instantly by the learners. The u-learning environment is interactive which allows learners to interact with teachers, peers, and experts effectively and efficiently via different media. Furthermore, u-learning is context-aware where the environment can adjust to learners' real situations to necessitate adequate information for them [1-3]. U-learning has progressed in the recent unprecedented times of COVID19 and climate change and its adoption is considered germane as conventional teaching and learning [4].

It is necessary to investigate scientific works in u-learning to understand the impact of scientific approaches in this evolving technology for teaching and learning that education systems around the globe have become increasingly reliant on. A systematic review and meta-analysis can put into perspective what studies have been conducted and expose gaps that exist for future studies. A systematic review provides an objective high-level overview on a research topic until present state. A meta-analysis is a statistical means of integrating diverse studies in a research area [5]. Limitations in existing work from the literature show that the impact of Artificial Intelligence and its applications in u-learning frameworks is not sufficiently addressed as a collective.

The systematic review and meta-analysis proposed by the authors have two main goals: 1) To present the evolution of artificial intelligence (AI) works in u-learning to map out the terrain for future scientific studies. 2) Highlight and analyze the specific application areas of predominate AI Algorithms in u-learning. This meta-analysis paper will provide more information to ensure that practitioners on the ground make well informed educational decisions on u-learning implementation and that scientific researchers gain valuable insights to make better research decisions for future trends.

\section{RELATED WORKS}

In the study by Meyliana, Hidayanto and Budiardjo in [6], students' social media preference was analysed to increase student engagement with the university. Data was collected from 1021 students from fifty-eight Indonesian Universities using questionnaires. Entropy was used to process data and assign criteria weights for social media preference. Using the TOPSIS (Technique for Order Preference by Similarity to the Ideal Solution) method, it was established that the implementation of social media was more dependent on information quality as opposed to service quality. However, while comprehensiveness and usefulness of information was highly essential to students, they also valued system availability, efficiency, and fulfilment as it directly impacted their expectation and active learning process. TOPSIS was also used to rate the social media platforms which resulted in 
LINE being the best social media platform and Podcast being the least likely platform to enhance student engagement with universities [6].

Since the advent of the primary Social Networking Site (SNS) as a novel way of communicating with other people, a lot of research has tried to identify theoretically and empirically the history of, the impact on, and the characteristics of the relationship between users and the SNS. There exists a behavioural studies research gap on the reasons why users join and participate in SNSs [7]. The study by Rad, Dahlan, Iahad, Nilashi and Ibrahim in [7] explored the influential factors causing users to adopt an SNS. A multicriteria decision-making (MCDM) tool, fuzzy AHP (Analytical Hierarchy Process) was used to evaluate the level of importance that literature derived factors such as: performance expectancy, social influence, effort expectancy, trust, facilitating conditions, privacy, perceived enjoyment, self-efficacy, and attitude toward technology had on the adoption of an SNS. Data was collected from 291 University students in the field of SNS via questionnaires and the findings of the study were that trust, performance expectancy and security were critical influential facts in SNS adoption [7].

It is apparent that technology has changed the landscape of the learning environment and that the way in which school learners learn is enhanced by different modes of education. Classroom technology incorporates interactive learning technology such as e-book technology. In Malaysia, the acceptance of novel technology like e-book technology by school children was considered important [8]. The study by Elyazgi, Nilashi, Ibrahim, Rayhan and Elyazgi in [8], identified the interface factors of CCI (Children Computer Interaction) and the determinants of usability guiding e-book behavioural acceptance by 417 school learners. The combination of the TAM (Technology Acceptance Model) and the e-book technology-related literature review, the research hypotheses were established from the interrelationship of a detailed set of constructs. The research hypotheses built the measurement framework, which was quantified by a structured questionnaire comprising a fivepoint Likert scale. Using the questionnaire and TOPSIS the importance of interface factors was deuced. The analysis of data indicated positive results about perceived ease of use, perceived usefulness, learner behaviour, usability, and interface. The combination of CCI and TAM factors afforded results that showed that school learners accepted the use of ebooks. The highest ranking was awarded to perceived ease of use whilst the lowest ranking was behaviour intention. The former was attributed to the functions and features of e-books which seemed to be easy to use. However, it was concerning that the e-book technology usability scale was lower than the interface scale, which inferred that school learners' e-book technology acceptance will improve if it is viewed as championing an elevated level of interactivity [8].

The paper by Omorogbe and Igbinosun in [9] examined the attributes that parents considered for school choice enrolment of their children or wards. Twelve attributes from four categories of school alternatives were studied in this work. In Benin City, a survey was indiscriminately conducted in the three local government areas. The AHP was implemented to evaluate the attributes and intuitionist fuzzy TOPSIS was applied to rank the alternatives. The correctness and consistency of results were affirmed by the two metric functions that were used both producing the same result. The ranking of the schools was as follows in descending order: The Missionary schools (A4), private schools for middle class (A2), the premier private schools for the elite (A3), and the Public (government) schools (A1). It was concluded that by implementing a scientific approach to a humanistic system, appropriate and accurate results can be produced.

The study by Pires and Cota in [10], focused on developing a self-regulating adaptive intelligent system to enhance special education needs, extending the paradigm to special education needs, using non-linear methods to correct the learning path to cater for individual special needs, and extending the research paradigm to u-learning. The study was founded on inclusive education and multiple intelligences such that special needs learners were able to fill cognitive gaps in their learning process. The proposed architecture of the system was based on an intelligent structure supplemented by a Genetic Algorithm (GA) and a Chi-square statistical function. The study involved a sample population of 13600 kindergarten learners of mixed abilities who were subject to an intelligent system comprising a Java developed GA module, and a XML \& SCORM based module consisting of an LMS (learning management system) such as Moodle and a Knowledge Block repository [10].

The study by Angeli, Howard, Ma, Yang, and Kirschner [11] explained and addressed several key questions on the utilisation of data mining in educational technology classroom research. Previous studies conducted in Australia and Europe which used the data mining techniques fuzzy representations and association rules mining were presented as examples in this study. These studies investigated 115 university student and 12978 school learners' behaviours, experiences, and learning within computer-assisted classroom activities. In the study employing fuzzy representations, questionnaire data was inductively explored. This study aptly depicted how data mining could be used by educational technologists to monitor and guide the integration of school-based technology. The inferences of the study were reviewed based on the need to create educational data mining tools that could present information, results, comments, explanations, and recommendations in profound ways to novice users in data mining such as teachers. The study using association rules mining involved comprehension clarity on how learners with cognitive differences interact with a simulation in problem solving. The study used Statistica as a data mining tool and illustrated how data mining could be employed to enhance evaluation practices of educational software in the educational technology field. Finally, matters associated with data privacy were addressed in both studies [11].

A high accuracy of students' performance prediction is useful in identifying the low performing students at the start of the learning process. This objective is achieved by machine learning where techniques are employed to uncover patterns or models of data which is valuable in decision-making [12]. The study by Belachew and Gobena in [12] applied machine learning concepts to the dataset obtained from the college of 
computing and informatics of Wolkite University registries office. The study collected 1071 student's transcript data that consisted of their grades in all courses and their final GPA (Grade Point Average). Machine learning methods, Naïve Bayesian, Support Vector Machine (SMO) and Neural Networks were applied after pre-processing the data. Lastly, a model for each method was developed, and the performance and results of each model was evaluated. The aim of the study was to create a model using machine learning to derive conclusions on students' academic performance [12].

Information and communications technology (ICT) have become very important in all spheres of human life. They are utilized in various fields as information systems (IS) using numerous telecommunication media to afford end-users the capability to control digital data [13]. Additionally, the development of relatively new technology, propagated distance learning through e-Learning platforms in the last two decades. Recommendation systems have become progressively used in IS, more so in e-learning platforms. These systems operate to recommend and propose content of these platforms to end-users corresponding to their needs to allot the most information for learning [13].

The paper by El Mabrouk, Gaou and Rtili in [13], presented a data mining based intelligent hybrid recommendation system using Neural networks, Bayesian networks and Decision trees with a population size of 700 university students. This system comprised four parts. The first part for data collection and centre of interest creation was done via two modes, namely: explicit data collection which was based on end-users and what they entered on their profiles, and automatic and implicit data collection by offering a survey to users to gather information about their interest. The second part involved managing the information previously collected and developing the learning model, to categorise users who posted the content and catalogue content to forward the results to the recommendation module. The third part drew parallels between content and learners and made recommendations for learners. The fourth part created a recommendation by learner log file which was used in the upcoming recommendation. The results of the study proposition were satisfactory, and the system was optimised with regards to response, processing time and accuracy when compared to traditional recommendation [13].

To effectively execute critical pedagogical interventions for students' satisfactory and on-time graduation, students' future performance based on their academic records must be predicted accurately. Student performance in completing degrees' prediction has limited studies conducted which results in several new challenges such as: the disparity of student's differences regarding selected courses and backgrounds; courses are not uniformly informative in making accurate predictions; and the incorporation of students' evolving progress needs into the prediction [14]. The study by $\mathrm{Xu}$, Moon and van der Schaar [14] developed a new machine learning method for student performance prediction in degree courses that could address the aforementioned key challenges. There were two major features of the proposed method: the first feature was a bilayered structure consisting of various base predictors and a flow of ensemble predictors to make predictions on students' progressing performance; the second feature was a data-driven approach built on probabilistic matrix factorization and latent factor models to unearth course relevance, which is imperative for creating efficient base predictors. With extensive simulations on a dataset of 1169 university students collected over three years, the study revealed that the proposed method achieved greater performance compared to benchmark approaches [14].

The study by Khoshi, Gooshki and Mahmoudi in [15] used fuzzy TOPSIS and AHP to prioritise the effective qualifications of medical lecturers from the opinion of medical students from the allied Tehran University of Medical Sciences in 2013 to 2014. Two hundred medical students were chosen based on random sampling method and were surveyed in accordance with Cochran's formula. Research based questionnaires were used as data collection tools that were divided professional, technical, and individual parts. Experts approved content validity. By calculating the Cronbach's alpha $(\alpha=0,85)$, reliability was confirmed by measuring the internal cohesion degree [15].

A commonly employed approach for student modelling is Bayesian Knowledge Tracing (BKT). It is a commonly used approach for student modelling. A versatile model that can be used for various tasks is Long Short-Term Memory (LSTM) [16]. The study by Mao, Lin and Chi in [16] compared BKT, a derivative IBKT (Intervention-BKT) and LSTM based on two student modelling tasks; learning gains and post-test scores prediction. An automatic skill discovery method (SK) was incorporated into all three models which augmented the exercise-skill assignments with a nonparametric prior. A total of six models was explored: IBKT, IBKT+SK, BKT, BKT+SK, LSTM, and LSTM+SK. One training dataset was collected from Cordillera which is a language physics intelligent tutoring system. The other training dataset was collected from Pyrenees which is a standard probability intelligent tutoring system. The results of the study revealed that BKT and BKT+SK outdid the other models on post-test scores prediction. Additionally, LSTM and LSTM+SK attained the highest area under the ROC curve (AUC), F1measure, and accuracy on learning gains prediction. Moreover, the study demonstrated that the BKT+SK combination could dependably predict post-test scores only using the first $50 \%$ of the total training sequences. For early prediction of learning gain, making use of the first $70 \%$ of the total training sequences, LSTM delivered an equivalent prediction using all of the training sequences. The findings of the study revealed a learning environment that could predict learning gains and students' performance early and could afford an adaptive pedagogical strategy appropriately [16].

The study by Mohamed and Lamia in [17], involved the use of computers, tablets, smartphones, and other smart devices as auxiliary tools of contemporary teaching and learning methods. The flipped classroom approach was used as an element of IOT (Internet of Things) to encourage problem solving in a mathematical logic course both in and out of the classroom via an ITS (Intelligent Tutoring System). The sample population was 50 university students and the researchers employed on-way ANOVA to determine the effectiveness of the flipped classrooms. This study showed 
that self-efficacy, perceived usefulness, perceived support, and compatibility for improving social ties are imperative precursors for continued use of flipped classrooms [17].

The study by Sirait, Fitriani, Hidayanto, Purwandari and Kosandi in [18] determined eleven criteria of social media platform selection to increase student participation in government activities and eight alternatives that best aligned to the criteria. Sirait et al. (2018) also established an order for assessing social media preferences and highlighted the social media that were popular to assist e-participation. Criteria generated was based on the theory of hedonic and utilitarian motivation. Data was collected from University students in Indonesia through a questionnaire and was processed via fuzzy AHP to ascertain the weight of social media to enhance e-participation in government activities. The TOPSIS method was employed to establish social media preferences. The results revealed that system quality of high importance along with hedonic gratification and information quality. The best SM application for student e-participation in priority order was: Line, Instagram, Path, YouTube, Facebook, Twitter, Blog and Wiki's [18].

Adaptive e-learning platforms offer personalized learning process mainly depending on learning styles. The conventional way of finding learning styles relies on requesting learners to evaluate their own behaviours and attitudes through questionnaires and surveys. This method renders several weaknesses such as the lack of learners' selfawareness of their own inclinations. Additionally, most learners feel bored when asked to complete a questionnaire and the conventional way presumes that learning styles cannot alter over time [19]. The paper by El Aissaoui, Oughdir and El Allioui in [19] proposed a generic approach for automatically identifying learning styles corresponding to a specific learning styles model. The study comprised two major steps: firstly, using web mining techniques to extract learning sequences from learners' log files on the Moodle platform; and secondly, using clustering algorithms to classify the extracted sequences via a specific learning style model. This experimental study was performed using a classification Learning Style Model called Felder-Silverman Model (FSM) and a clustering algorithm called Fuzzy C-Means and used a real-world dataset of 1235 university students. The goodness of the study's approach was compared with the K-means algorithm, MCQ method and the FCM algorithm. The results revealed that this two-step approach proved to be promising and outperformed traditional approaches [19].

Grouping learners specifically in high school is an essential process to classify and divide them into classes based on their interests and abilities as it helps them to thrive. Most schools apply academic grades to group learners but there are other approaches that exist. As this is an annual task with new learners, both the teachers and learners feel overwhelmed with grouping [20]. A solution to this repetitive task may be the implementation of a decision support system that can automate the grouping process. An example of an unsupervised learning algorithm is a SOM (self-organising map) which uses an artificial neural network structure to afford a reduced dimensional representation of the given input. SOM is also a clustering technique [20]. The study by Purbasari, Puspaningrum and Putra [20] used SOM to academically group 275 school learners based on their national examination results and rapport books into three distinct clusters, namely, Social Sciences, Life Sciences and Linguistics.

It is a valuable endeavour for any educational institution to predict students' academic performance as the predictions can assist educators in supporting students who are at risk of failure. The process of educational data mining (EDM) is a machine learning and data mining technique which above other tasks can predict students' performance [21]. The study by El Aissaoui, El Alami El Madani, Oughdir, Dakkak and El Allioui in [21] proposed a methodology to create a student performance prediction model using multiple linear regression (MLR) which is a supervised machine learning technique. The three major steps of the methodology were: 1) pre-processing and analysing the variables/attributes of students using a group of statistical analysis methods; 2) using different methods for selecting the most crucial variables; 3) constructing diverse MLR models centred on the variables selected and using the $\mathrm{k}$-fold cross-validation technique for comparing the 395 students' academic performance. The results obtained revealed that the model derived from the selected variables of the MARS (Multivariate Adaptive Regression Splines) method, outperformed the other constructed models [21].

AI methods, namely, Intelligent Decision Support Systems, Intelligent Systems, Educational Data Mining (EDM) and Machine Learning are captured in Table I below. Table I is categorised according to the following fields: Number (\#), Authors, Year, Artificial Intelligence Methods and Techniques, Problem Focus, Number of Algorithms, Number of Datasets, Number of Variables and Size. The table captures studies in Artificial Intelligence in u-learning from 2015 to 2020. The problem focus column suggests that there were lots of studies conducted in higher education and fewer studies in school based education.

Table I also shows the techniques employed by each Artificial Intelligence method. The study numbers can be used to reference the study in the table. Intelligent Decision Support Systems techniques used were: Entropy (\#1), TOPSIS (\#1, \#3, \#13), AHP (\#2, \#4, \#10, \#13) and Fuzzy TOPSIS (\#10). Intelligent Systems techniques used were: Genetic Algorithms (\#5), ANOVA (\#12) and Self Organising Maps (\#15). Education Data Mining (EDM) techniques used were: Data Mining (\#6). Lastly, Machine Learning techniques used were: Neural Networks (\#7, \#8), Naïve Bayes (\#7, \#8, \#11, \#14), Support Vector Machines (\#7), Ensemble methods (\#9), Deep Learning (\#11), Clustering (\#14) and K-fold cross validation (\#16). 
TABLE I. ARTIFICIAL INTELLIGENCE WORKS APPLIED IN U-LEARNING (2015-2020)

\begin{tabular}{|c|c|c|c|c|c|c|c|c|}
\hline$\#$ & Authors & Year & $\begin{array}{l}\text { Artificial Intelligence Methods } \\
\text { and Techniques }\end{array}$ & Problem Focus & 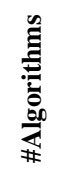 & 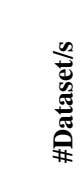 & 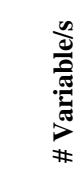 & is \\
\hline 1. & $\begin{array}{l}\text { Meyliana, M., A.N. } \\
\text { Hidayanto, and E.K. } \\
\text { Budiardjo }\end{array}$ & 2015 & $\begin{array}{l}\text { Intelligent Decision Support } \\
\text { Systems } \\
\text { Entropy and TOPSIS Method } \\
10 \text { alternatives }\end{array}$ & $\begin{array}{l}\text { Social Media preference for } \\
\text { student engagement } \\
\text { improvement in universities. }\end{array}$ & 2 & 1 & 7 & $\begin{array}{l}1021 \\
\text { University } \\
\text { students }\end{array}$ \\
\hline 2. & $\begin{array}{l}\text { Rad, M.S., Dahlan, } \\
\text { H.M, Iahad, N.A, } \\
\text { Nilashi, M. and } \\
\text { Ibrahim, O. }\end{array}$ & 2015 & $\begin{array}{l}\text { Intelligent Decision Support } \\
\text { Systems } \\
\text { Fuzzy AHP }\end{array}$ & $\begin{array}{l}\text { Using a Multi-Criteria } \\
\text { Decision-Making Approach } \\
\text { for Assessing the Factors } \\
\text { Affecting Social Network } \\
\text { Sites Intention to Use. }\end{array}$ & 1 & 1 & 10 & $\begin{array}{l}291 \text { University } \\
\text { Students }\end{array}$ \\
\hline 3. & $\begin{array}{l}\text { Elyazgi, M.G., } \\
\text { Nilashi, M., Ibrahim, } \\
\text { O., Rayhan, A. and } \\
\text { Elyazgi, S }\end{array}$ & 2016 & $\begin{array}{l}\text { Intelligent Decision Support } \\
\text { Systems } \\
\text { Technique for Order Preference } \\
\text { by Similarity to Ideal Solution } \\
\text { (TOPSIS) } \\
6 \text { criteria/34 indexes } \\
\end{array}$ & $\begin{array}{l}\text { Evaluating the Factors } \\
\text { Influencing E-book } \\
\text { Technology Acceptance } \\
\text { among School Children Using } \\
\text { TOPSIS Technique. }\end{array}$ & 1 & 1 & 34 & $\begin{array}{l}417 \\
\text { School } \\
\text { Learners }\end{array}$ \\
\hline 4. & $\begin{array}{l}\text { Omorogbe, D. E. A. } \\
\text { and Igbinosun, L. I. }\end{array}$ & 2016 & $\begin{array}{l}\text { Intelligent Decision Support } \\
\text { Systems } \\
\text { integrated AHP-intuitionistic } \\
\text { fuzzy TOPSIS } \\
4 \text { alternatives }\end{array}$ & $\begin{array}{l}\text { Parents Preference for } \\
\text { Students' Choice of Urban } \\
\text { Schools in Benin City, } \\
\text { Nigeria: Integrated AHP } \\
\text { Intuitionistic Fuzzy TOPSIS. }\end{array}$ & 1 & 1 & 12 & $\begin{array}{l}144 \\
\text { Parents }\end{array}$ \\
\hline 5. & $\begin{array}{l}\text { Pires, J.M. and Cota, } \\
\text { M.P. }\end{array}$ & 2016 & $\begin{array}{l}\text { Intelligent Systems } \\
\text { Genetic Algorithm } \\
\text { The Chi-Square function }\end{array}$ & $\begin{array}{l}\text { "Intelligent" Adaptive } \\
\text { Learning Objects applied to } \\
\text { Special Education needs } \\
\text { Extending the eLearning } \\
\text { paradigm to the u-Learning } \\
\text { environment. }\end{array}$ & 2 & 1 & 4 & $\begin{array}{l}13600 \\
\text { Kindergarten } \\
\text { Learners }\end{array}$ \\
\hline 6. & $\begin{array}{l}\text { Angeli, C., Howard, } \\
\text { S.K. Ma, J.,Yang, J. } \\
\text { and Kirschner, P.A. }\end{array}$ & 2017 & $\begin{array}{l}\text { Educational Data Mining } \\
\text { (EDM) } \\
\text { Association Rules } \\
\text { Fuzzy Representations }\end{array}$ & $\begin{array}{l}\text { Data mining in educational } \\
\text { technology classroom } \\
\text { research: Can it make a } \\
\text { contribution? }\end{array}$ & 2 & 2 & 6 & $\begin{array}{l}115 \\
\text { University } \\
\text { students } \\
12978 \\
\text { School } \\
\text { Learners }\end{array}$ \\
\hline 7. & $\begin{array}{l}\text { Belachew, E.B. and } \\
\text { Gobena, F.A. }\end{array}$ & 2017 & $\begin{array}{l}\text { Machine Learning } \\
\text { Neural Networks, Naive } \\
\text { Bayesian and Support Vector } \\
\text { Machine }\end{array}$ & $\begin{array}{l}\text { Student Performance } \\
\text { Prediction Model using } \\
\text { Machine Learning Approach: } \\
\text { The Case of Wolkite } \\
\text { University. }\end{array}$ & 3 & 1 & 6 & $\begin{array}{l}1071 \\
\text { University } \\
\text { students }\end{array}$ \\
\hline 8. & $\begin{array}{l}\text { El Mabrouk, M., } \\
\text { Gaou, S. and Rtili, } \\
\text { M.K. }\end{array}$ & 2017 & $\begin{array}{l}\text { Machine Learning } \\
\text { Neural networks, Bayesian } \\
\text { networks and Decision trees. } \\
1000 \text { evaluations }\end{array}$ & $\begin{array}{l}\text { Towards an Intelligent Hybrid } \\
\text { Recommendation System for } \\
\text { E-Learning Platforms Using } \\
\text { Data Mining. }\end{array}$ & 1 & 1 & 1000 & $\begin{array}{l}700 \\
\text { University } \\
\text { Students }\end{array}$ \\
\hline 9. & $\begin{array}{l}\text { Xu, J., Moon, K.H. } \\
\text { and van der Schaar, } \\
\text { M. }\end{array}$ & 2017 & $\begin{array}{l}\text { Machine Learning } \\
\text { A prediction layer and an } \\
\text { ensemble prediction layer }\end{array}$ & $\begin{array}{l}\text { Predicting students' future } \\
\text { performance based on their } \\
\text { ongoing academic records. }\end{array}$ & 2 & 1 & 5 & $\begin{array}{l}1169 \\
\text { University } \\
\text { students }\end{array}$ \\
\hline 10. & $\begin{array}{l}\text { Khoshi, A., Gooshki, } \\
\text { H.S. and Mahmoudi, } \\
\text { N. }\end{array}$ & 2018 & $\begin{array}{l}\text { Intelligent Decision Support } \\
\text { Systems } \\
\text { Combined Fuzzy AHP and } \\
\text { Fuzzy TOPSIS }\end{array}$ & $\begin{array}{l}\text { Hybrid Fuzzy AHP and Fuzzy } \\
\text { TOPSIS to prioritise the } \\
\text { qualifications of teachers. } 6 \\
\text { criteria, } \\
17 \text { indexes. }\end{array}$ & 2 & 1 & 6 & $\begin{array}{l}200 \\
\text { University } \\
\text { Students }\end{array}$ \\
\hline 11. & $\begin{array}{l}\text { Mao, Y. Lin, C. and } \\
\text { Chi, M. }\end{array}$ & 2018 & $\begin{array}{l}\text { Machine Learning } \\
\text { Long Short-Term Memory } \\
\text { (LSTM) } \\
\text { Bayesian Knowledge Tracing } \\
\text { (BKT) } \\
\text { Intervention- (IBKT) in } \\
\text { combination with a Skills } \\
\text { discovery method (SK) }\end{array}$ & $\begin{array}{l}\text { Bayesian Knowledge Tracing } \\
\text { (BKT) for predicting } \\
\text { students' performance- } \\
\text { Learning gains prediction and } \\
\text { Test score prediction. }\end{array}$ & 6 & 2 & $\begin{array}{l}33 \\
11\end{array}$ & $\begin{array}{l}169 \text { University } \\
\text { students } \\
475 \text { University } \\
\text { students }\end{array}$ \\
\hline
\end{tabular}




\begin{tabular}{|c|c|c|c|c|c|c|c|c|}
\hline 12. & $\begin{array}{l}\text { Mohamed, H. and } \\
\text { Lamia, M. }\end{array}$ & 2018 & $\begin{array}{l}\text { Intelligent Systems } \\
\text { ANOVA }\end{array}$ & $\begin{array}{l}\text { Flipped classroom as an } \\
\text { element of Internet of Things } \\
\text { (IoT) into learning process. }\end{array}$ & 1 & 1 & 9 & $\begin{array}{l}50 \\
\text { University } \\
\text { Students }\end{array}$ \\
\hline 13. & $\begin{array}{l}\text { Sirait, A.D.S., Fitriani, } \\
\text { W.R., Hidayanto, } \\
\text { A.N., Purwandari, B. } \\
\text { and Kosandi, M. }\end{array}$ & 2018 & $\begin{array}{l}\text { Intelligent Decision Support } \\
\text { Systems } \\
\text { Fuzzy AHP } \\
\text { TOPSIS }\end{array}$ & $\begin{array}{l}\text { Social media to support the } \\
\text { development of e- } \\
\text { government. } \\
8 \text { alternatives. }\end{array}$ & 2 & 1 & 11 & $\begin{array}{l}401 \text { University } \\
\text { students }\end{array}$ \\
\hline 14. & $\begin{array}{l}\text { El Aissaoui, O., } \\
\text { Oughdir, L. and El } \\
\text { Allioui, Y. }\end{array}$ & 2019 & $\begin{array}{l}\text { Machine Learning } \\
\text { Unsupervised algorithm (K- } \\
\text { means) for grouping } \\
\text { supervised algorithm (Naive } \\
\text { Bayes) for classification }\end{array}$ & $\begin{array}{l}\text { Adaptive e-learning system } \\
\text { for detecting learning styles } \\
\text { automatically. }\end{array}$ & 2 & 1 & 17 & $\begin{array}{l}1235 \\
\text { University } \\
\text { Students }\end{array}$ \\
\hline 15. & $\begin{array}{l}\text { Purbasari, I.Y., } \\
\text { Puspaningrum, E.Y. } \\
\text { and Putra, A.B.S. }\end{array}$ & 2019 & $\begin{array}{l}\text { Intelligent Systems } \\
\text { Self-Organizing Map (SOM) } \\
\text { algorithm }\end{array}$ & $\begin{array}{l}\text { An intelligent system which } \\
\text { can automatically perform } \\
\text { grouping on a list of students. }\end{array}$ & 1 & 1 & 9 & $\begin{array}{l}275 \\
\text { School } \\
\text { Learners }\end{array}$ \\
\hline 16. & $\begin{array}{l}\text { El Aissaoui, O., El } \\
\text { Alami El Madani, Y., } \\
\text { Oughdir, L., Dakkak, } \\
\text { A. and } \\
\text { El Allioui, Y. }\end{array}$ & 2020 & $\begin{array}{l}\text { Educational Data Mining } \\
\text { (EDM) } \\
\text { Data mining and machine } \\
\text { learning techniques } \\
\text { multiple linear regression } \\
\text { (MLR) } \\
\text { k-fold cross-validation } \\
\text { technique }\end{array}$ & $\begin{array}{l}\text { A Multiple Linear } \\
\text { Regression-Based Approach } \\
\text { to Predict Student } \\
\text { Performance. }\end{array}$ & 7 & 1 & 32 & $\begin{array}{l}395 \\
\text { School } \\
\text { Learners }\end{array}$ \\
\hline
\end{tabular}

\section{MAterials AND MethodS}

\section{A. PRISMA}

Preferred Reporting Items for Systematic Reviews and Meta-Analyses (PRISMA) is an evidence based least group of items for writing a report in meta-analyses and systematic reviews. PRISMA concentrates on giving an account of reviews and is employed as the foundation for reporting systematic reviews, specifically intervention evaluation [22]. Meta-analyses and systematic reviews are methodologically rigorous studies that establish the reference standard for developing evidence in various clinical, business fields and scientific studies [23]. The number of studies makes it essential to ensure reporting transparency and quality are strictly followed. It is important to note study quality and reporting quality are not congruent, a feebly reported study is of inadequate value as it is difficult to make a transparent and complete judgment of its value in the absence of all the required information [24].

A study that has been conducted well may be reported poorly and perhaps eclipsed by its reporting [24]. It is a proven fact that digression from the reporting guidelines in meta-analyses and systematic reviews can result in bias [25]. Such work has consequently led to the development of the PRISMA statement which is a twenty-seven-item checklist ensuring transparency in the reporting of a review [25]. Given the upsurge of systematic reviews in e-learning, m-learning, and u-learning it is crucial to ensure reviews are effectively reported. The current study is appositely reported using the PRISMA methodology to ensure education researchers, scientific method researchers, policy makers and instructors can make transparent and complete judgements to steer key scientific or education decisions.

In this meta-analysis and systematic review, the following databases were searched for and afforded the most applicable published articles: ScienceDirect, Semantic Scholar, SpringerLink, IEEE, Google Scholar, and Academia. Other databases affording fewer applicable articles were Educase, Hindawi, Science Publishing Group, Taylor \& Francis, MDPI, Modestum, Scopus, Eric, SAGE Journals, Emerald, and World Scientific. These databases were restricted to English papers published between 2015 to 2020 using the following combination of terms: Intelligent Decision Support Systems, Intelligent Systems, Machine Learning, Data Mining, Educational Data Mining, Ubiquitous Learning, u-learning, elearning and m-learning. The search terms were separated or combined using Boolean operators such as 'OR', 'AND' and 'NOT'. The studies identified by the search strategies were downloaded. A total of 330 published articles between the years 2015 and 2020 were identified as depicted in Fig. 1. The abstract and introduction sections were read in order to determine the eligibility the papers dealing with scientific methods used in u-learning research. As a corresponding process, reference lists of the appropriate studies were manually checked for any citations omitted by the electronic database searching. The scope was reduced to 16 scientific works which was analyzed in-depth in the meta-analysis.

\section{B. Inclusion Criteria}

As the focus of the study was on scientific methods used in u-learning studies, the criteria for inclusion of the articles were: Intelligent Systems (IS), Intelligent Decision Support Systems (IDSS), Machine Learning (ML); and Educational Data Mining (EDM) which were applied to u-learning studies. Since u-learning comprises e-learning and m-learning, these factors were also added to the inclusion criteria [26]. Additionally, the inclusion criteria were specific to scientific methods used in u-learning in school-based and university education.

\section{Intelligent Systems (IS)}

IS are technically innovative and autonomous systems that sense and react to the physical and social world to achieve human users' goals. A study of how computers can comprehend and translate video sequences and static images into visual information emerged between the 1950's to 1960's 
and has since evolved into a potent technology that is pivotal to most sectors such as education [10]. The fundamental factors that have attributed to this evolution are the exponential augmentation of the algorithms, memory capacity, and processor speed of technology. Research in intelligent systems faces numerous challenges, many of which relate to representing a dynamic physical world computationally [20].

\section{Intelligent Decision Support Systems (IDSS)}

IDSS is a decision support system that extensively uses AI techniques. AI techniques have been employed over a longstanding history as IS and knowledge-based systems in management IS [9]. Preferably, an IDSS should perform as a human consultant in helping decision makers to collect and examine evidence, detect and make a diagnosis on problems, and propose and evaluate solutions. The purpose of AI techniques rooted in an IDSS is to ensure that the previously mentioned tasks are completed by a computer under wellknown decision parameters, while closely mimicking expert human capabilities [9]. In research, AI directed towards allowing systems to react to innovation and indecision in more adaptable ways is beginning to be used in IDSS. For instance, intelligent agents that conduct difficult cognitive tasks without human involvement have been utilized in a variety of decision support applications [15]. Competences of these intelligent agents consist of machine learning, knowledge sharing, automated inference, and machine learning. An array of AI techniques like fuzzy logic, rough sets, and case-based reasoning have also been employed to facilitate better performance of decision support systems in uncertain conditions [15].

\section{E. Machine Learning (ML)}

ML involves computer algorithm studies that develop instinctively through experience [14]. It is a subgroup of AI. ML algorithms construct a mathematical model centred on training data (sample data), to make decisions or predictions without being overtly programmed to do so [16]. ML algorithms are employed in a vast array of applications, for instance with computer vision and email filtering, where it is complex and not feasible to create traditional algorithms to execute the desired tasks [19]. ML is closely associated to computational statistics, which involves making predictions with computers. The mathematical optimization studies afford application, theory, and technique domains to the machine learning field. Data mining is a connected field of study [19].

\section{F. Educational Data Mining (EDM)}

EDM is a developing discipline, involved with emerging methods for investigating the rare and progressively largescale data that are derived from educational settings. It also involves applying those methods to better comprehend learners, and the settings which they learn [11]. Irrespective of whether educational data is mined from; learners' use of administrative data from universities and schools, computer supported collaborative learning, or interactive learning environments; it frequently has numerous levels of evocative hierarchy, which need to be decided by the data properties, rather than in advance. Other impacting factors in the study of EDM are context, time, and sequence [21].

\section{G. Exclusion Criteria}

Articles that were excluded were: written in dialects other than English; published before January 2015; study designs such as letters to editors, reviews, commentaries, editorials, book chapters, books, expert opinions, books, theses, and brief reports; and scientific applications to enhance u-learning. Also, articles that neglected to account for the inclusion criteria were excluded. All non-scientific publications on $\mathrm{u}-$ learning were excluded. Fig. 1 shows the flow diagram of the study based on the PRISMA methodology.

\section{H. Quality Assessment}

Information that aligned with the inclusion criteria were rooted out from the chosen studies. The study with $100 \%$ correlation to the inclusion criteria was applicable for the meta-analysis and systematic review. The first author extracted the following information from the studies which met the inclusion criteria: the author's name, year of publication, scientific model, size, and algorithms. The first and second authors assessed the qualities of each article included by using a critical appraisal tool for use in the systematic review for a study examining artificial intelligence works in ubiquitous learning environments and technologies.

\section{Statistical Analysis}

Data were extracted in a Microsoft excel spreadsheet, and analysis was carried out using statistical software. Heterogeneity among reported prevalence was assessed by computing $p$ values of Higgins's $\mathrm{I}^{2}$ statistics; $\mathrm{I}^{2}$ was considered as significant at a p-value $<0.05$. The DerSimonian and Laird's random-effects meta-analysis model [28] was used to determine the pooled effect size since the actual effect is not the same in all studies. We deal heterogeneity with subgroup analysis, meta-regression, and sensitivity analysis. Subgroup analysis was done based on study scientific model approaches. Besides, an effort to understand the sources of heterogeneity, univariate metaregression analysis was conducted for sample size, and publication year. A forest plot [29] was used to describe pooled prevalence with $95 \%$ confidence intervals. The size of each box indicated the weight of the study, while each crossed line refers to a $95 \%$ confidence interval with the mean effect at the centre. The possibility of publication bias was assessed visually with funnel plots, and the objectivity test of Egger's test with a p-value less than 0.05 was considered evidence of publication bias. 


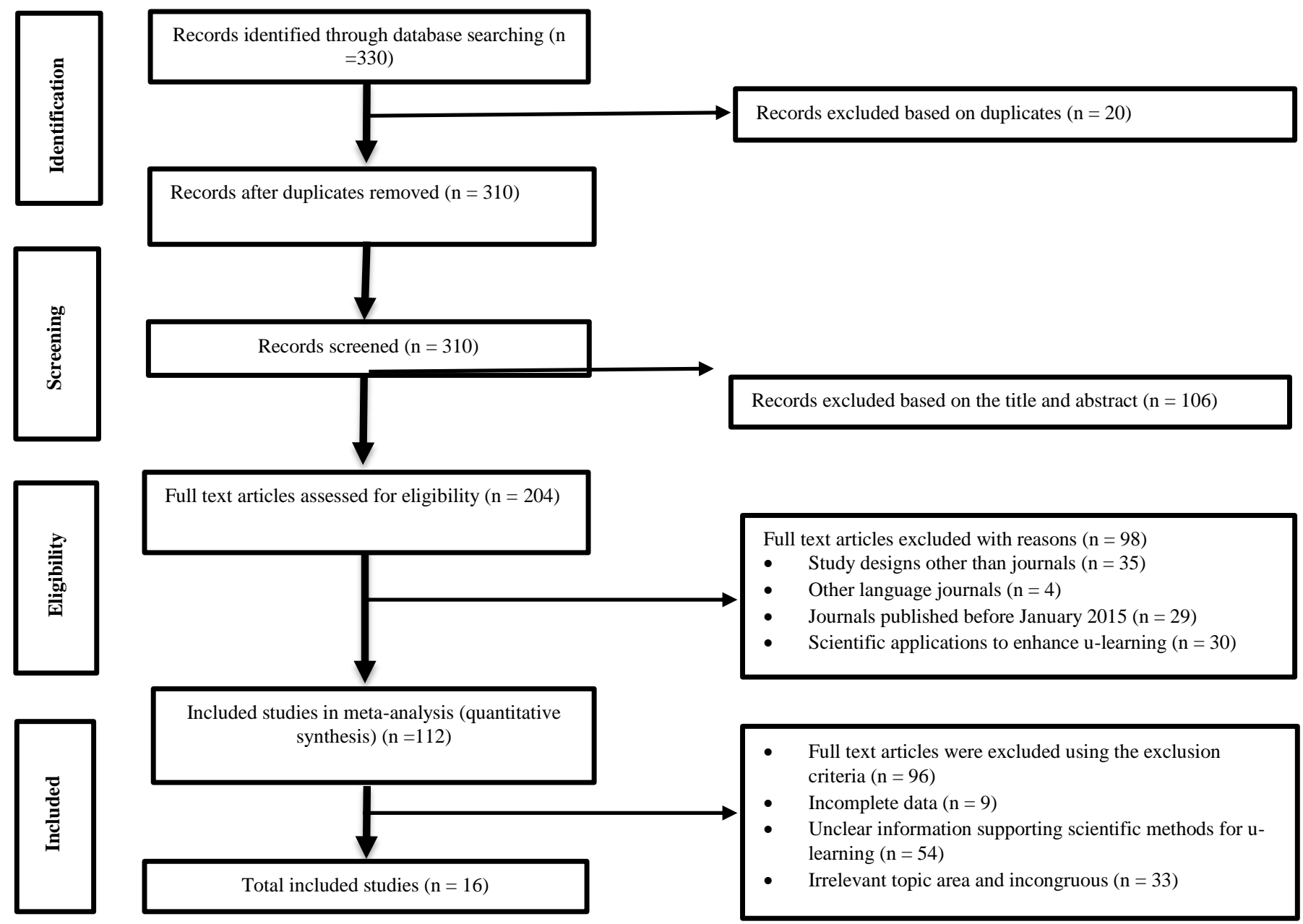

Fig. 1. Flow Diagram of the Database Searches (Preferred Reporting Items for Systematic Reviews and Meta-Analysis) Source: Moher, D., Liberati, A., Tetzlaff, J., Altman, D.G. and Group in [27].

\section{RESULTS}

The pooled estimate showed that there is statistically significant heterogeneity between the studies. Hence, this necessitated the use of random-effects model. Thus, using random-effects model [28], the estimated pooled estimate of artificial intelligence works in ubiquitous learning environments and technologies reported by the 16 studies was 10\% (95\% CI: 3\%, 22\%; $\left.\mathrm{I}^{2}=99.46 \%, \mathrm{P}=0.00\right)$ which indicates the presence of heterogeneity. The pooled estimate of artificial intelligence works in ubiquitous learning environments and technologies was presented using a forest plot (Fig. 2). From the forest plot in Fig. 2, the black dot at the centre of the grey box indicates the estimated prevalence point of each study, and the line indicates the $95 \%$ confidence interval of the estimates. The grey box indicates the weight of each study, contributing to the overall pooled prevalence estimate. The blue diamond represents the $95 \%$ confidence interval of the pooled rotavirus prevalence estimate.

\section{A. Subgroup Analysis based on the Scientific Model Approaches}

Subgroup analyses (Fig. 3) were carried out stratified scientific model approaches. The subgroup analysis by scientific model approaches was conducted to assess the potential heterogeneity between studies. Of the 16 studies, the highest pooled estimate was found in studies conducted with machine learning [18\% (95\% CI: $11 \%, 25 \%), \mathrm{I}^{2}=99.83 \%$ ] followed by studies conducted with intelligent systems [13\% $(95 \%$ CI: $\left.1 \%, 26 \%), \mathrm{I}^{2}=0.0 \%\right)$ while both intelligent decision support systems and educational data mining have the lowest percentage given as [7\%(95\% CI: $\left.3 \%, 11 \%), \mathrm{I}^{2}=95.21 \%\right]$ and [7\%(95\% CI: $\left.5 \%, 9 \%), \mathrm{I}^{2}=0.0 \%\right]$ respectively (Fig. 3). Meanwhile, the high heterogeneity could be as a result of significant variation in the number of students among various studies. 


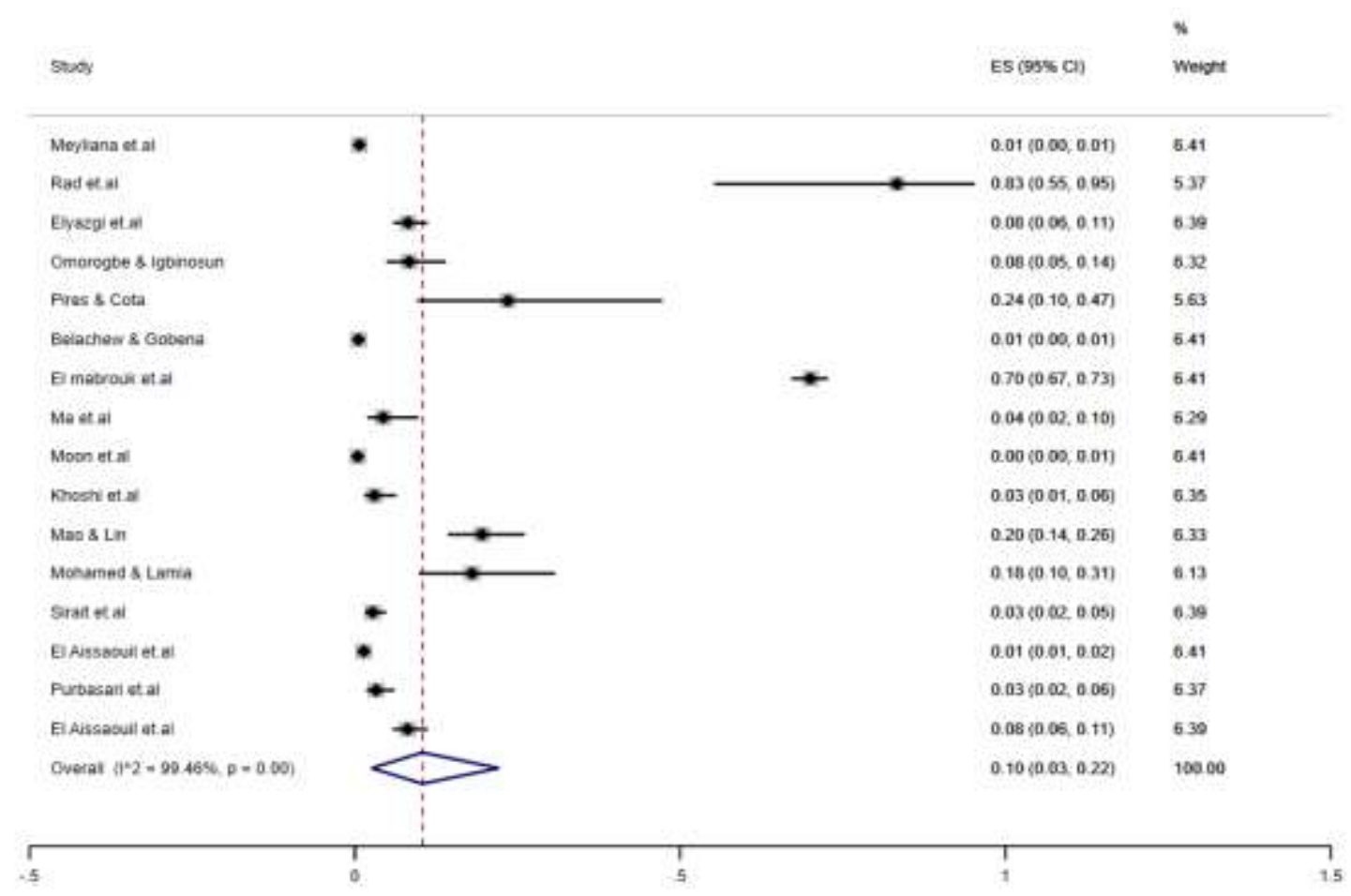

Fig. 2. Forest Plot Showing the Overall Pooled Estimate of Artificial Intelligence Works in ubiquitous Learning Environments and Technologies.

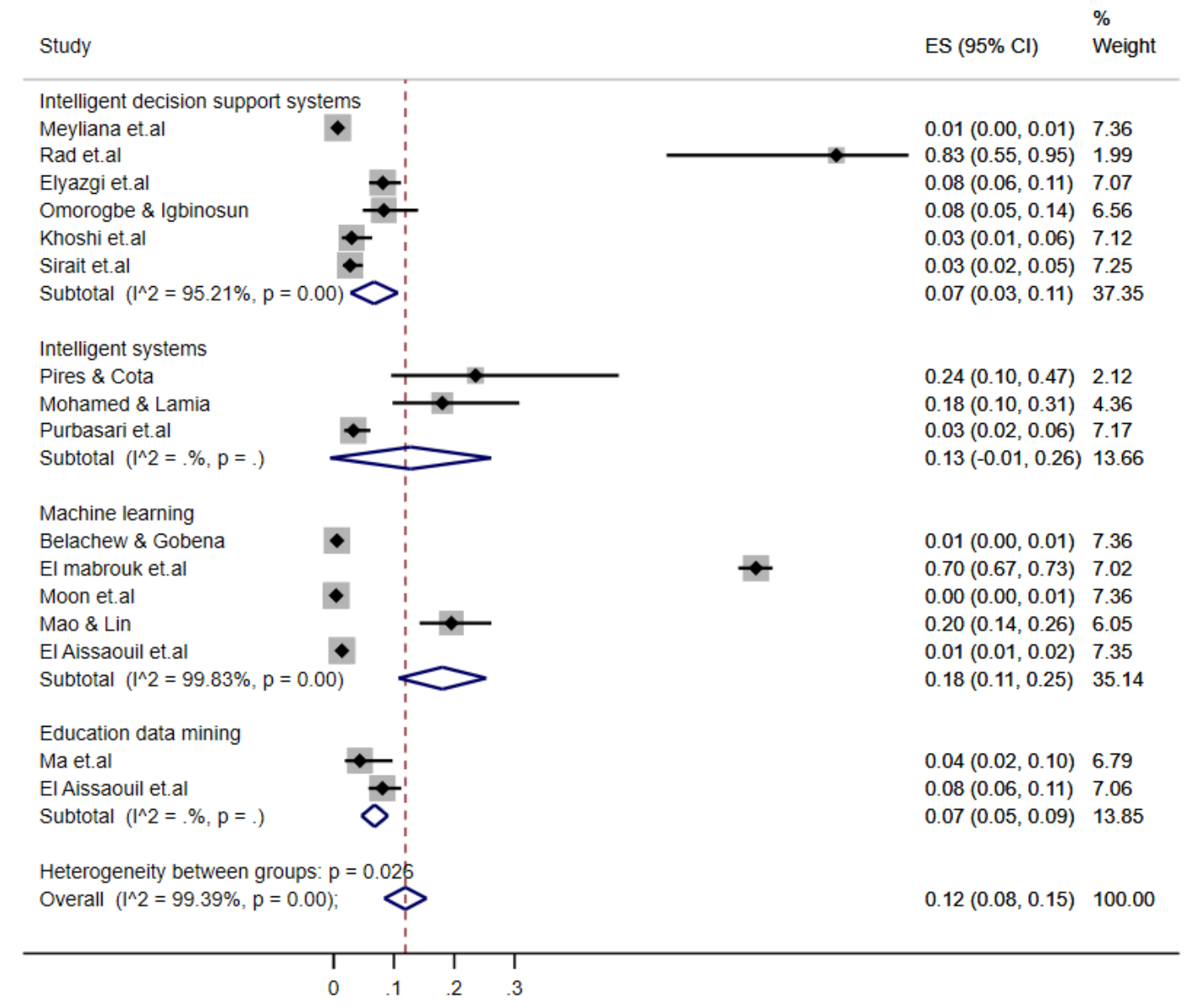

Fig. 3. Subgroup Analysis of Artificial Intelligence Works in ubiquitous Learning Environments and Technologies Stratified by Scientific Model Approaches. 


\section{CONCLUSION}

This study analysed different artificial intelligence works in ubiquitous learning environments and technologies based on the four major scientific approaches - intelligent decision support systems, intelligent systems, machine learning and educational data mining. The meta-analysis experimental result divulged that studies which used the machine learning approach gave the best result. Machine Learning studies have garnered significant interest and is variable in intervention effects being evaluated. Machine learning studies show heterogeneity in terms of sample size and variation in the choice of algorithms. Nevertheless, it does not mean that intelligent decision support systems, intelligent systems, and educational data mining are not efficient. The analysis show that while intelligent decision support systems is highly heterogeneous intelligent systems and educational data mining show no heterogeneity. It is observed from the studies that intelligent decision support systems although vary in intervention effects they have smaller datasets and employ fewer standard algorithms than studies in machine learning. Scope exists for future studies in all areas of artificial intelligence to proffer solutions in varied u-learning environments and technologies.

\section{ACKNOWLEDGMENT}

Kind acknowledgement goes to the Durban University of Technology for making the resources available for this research project.

\section{REFERENCES}

[1] Ogata, H. and Yuno, Y., Context-Aware Support for ComputerSupported Ubiquitous Learning., in Proceedings of the 2nd IEEE International Workshop on Wireless and Mobile Technologies in Education. 2004. p. 27 - 34.

[2] Chiu, P.S., Kuo, Y., Huang, Y. and Chen. T., A Meaningful Learning based u-Learning Evaluation Model, in Eighth IEEE International Conference on Advanced Learning Technologies. 2008. p. 77-81.

[3] Yahya, S., Ahmad, E.A. and Jalil, K.A., The definition and characteristics of ubiquitous learning: A discussion. International Journal of Education and Development using Information and Communication Technology, 2010. 6(1): p. 117-127.

[4] Miller, M.D., Going Online in a Hurry: What to Do and Where to Start. The chronical of higher education, Moving online now., 2020.

[5] Tabuenca, B., Wu, L. and Tovar, E., The PRISMA: A Visual Feedback Display for Learning Scenarios. in Proceedings of 13th International Conference on Ubiquitous Computing and Ambient Intelligence UCAml 2019, 2019. Toledo, Spain.

[6] Meyliana, M., Hidayanto, A.N. and Budiardjo, E.K., Evaluation of social media channel preference for student engagement improvement in universities using entropy and TOPSIS method. Journal of Industrial Engineering and Management, 2015. 8(5): p. 1676-1697.

[7] Rad, M.S., Dahlan, H.M, Iahad, N.A, Nilashi, M. and Ibrahim, O., Using a Multi-Criteria Decision-Making Approach for Assessing the Factors Affecting Social Network Sites Intention to Use. Journal of Soft Computing and Decision Support Systems 2015. 2(3): p. 20-28.

[8] Elyazgi, M.G., Nilashi, M., Ibrahim, O., Rayhan, A. and Elyazgi, S., Evaluating the Factors Influencing E-book Technology Acceptance among School Children Using TOPSIS Technique. Journal of Soft Computing and Decision Support Systems., 2016. 3(2): p. 11-25.
[9] Omorogbe, D.E.A.a.I., L.I. , Parents Preference for Students' Choice of Urban Schools in Benin City, Nigeria: Integrated AHP Intuitionistic Fuzzy TOPSIS. An International Multi-disciplinary Journal, Ethiopia., 2016. 10(2): p. 254-265.

[10] Pires, J.M.a.C., M.P. , "Intelligent" Adaptive Learning Objects applied to Special Education needs: Extending the eLearning paradigm to the uLearning environment, in 11th Iberian Conference on Information Systems and Technologies (CISTI). 2016: Las Palmas, Spain. p. 1-6.

[11] Angeli, C., Howard, S.K. Ma, J.,Yang, J. and Kirschner, P.A. , Data mining in educational technology classroom research: Can it make a contribution? . Computer and Education, 2017. 113: p. 226-242.

[12] Belachew, E.B.a.G., F.A. , Student Performance Prediction Model using Machine Learning Approach: The Case of Wolkite University. International Journal of Advanced Research in Computer Science and Software Engineering, 2017. 7(2): p. 46-50.

[13] El Mabrouk, M., Gaou, S. and Rtili, M.K. , Towards an Intelligent Hybrid Recommendation System for E-Learning Platforms Using Data Mining. International Journal of Emerging technologies in Learning, 2017. 12(6): p. 52-76.

[14] Xu, J., Moon, K.H. and van der Schaar, M., A Machine Learning Approach for Tracking and Predicting Student Performance in Degree Programs. IEEE Journal of Selected Topics in Signal Processing, 2017. 11(5): p. 742-753.

[15] Khoshi, A., Gooshki, H.S. and Mahmoudi, N. , The data on the effective qualifications of teachers in medical sciences: An application of combined fuzzy AHP and fuzzy TOPSIS methods. . Data in Brief, 2018. 21(2018): p. 2689-2693.

[16] Mao, Y., Lin, C. and Chi, M. , Deep Learning vs. Bayesian Knowledge Tracing: Student Models for Interventions. Journal of Educational Data Mining. , 2018. 10(2): p. 29-54.

[17] Mohamed, H. and Lamia, M. , Implementing flipped classroom that used an intelligent tutoring system into learning process Computers and Education, 2018. 124(2018): p. 62-76.

[18] Sirait, A.D.S., Fitriani, W.R., Hidayanto, A.N., Purwandari, B. and Kosandi, M. , Evaluation of social media preference as e-participation channel for students using fuzzy AHP and TOPSIS. In 4th International Conference on Computing, Engineering, and Design, ICCED 2018. 2019: Bangkok: Institute of Electrical and Electronics Engineers Inc. p. 158-163.

[19] El Aissaoui, O., Oughdir, L. and El Allioui, Y., A fuzzy classification approach for learning style prediction based on web mining technique in e-learning environments. . Education and Information Technologies, 2019. 24(2019): p. 1943-1959.

[20] Purbasari, I.Y., Puspaningrum, E.Y. and Putra, A.B.S. , Using SelfOrganizing Map (SOM) for Clustering and Visualization of New Students based on Grades. Journal of Physics: Conference Series, 2020. 1569(2020): p. 1-6.

[21] El Aissaoui, O., El Alami El Madani, Y., Oughdir, L., Dakkak, A. and El Allioui, Y., A Multiple Linear Regression-Based Approach to Predict Student Performance. Advanced Intelligent Systems for Sustainable Development, 2020. 1102(2020): p. 9-23.

[22] Chatzigeorgiou, I.M. and and Andreou, G.T., A systematic review on feedback research for residential energy behavior change through mobile and web interfaces. Renewable and Sustainable Energy Reviews, 2020. 135(2021): p. 1-16.

[23] Moher, D., Shamseer, L., Clarke, M., Ghersi, D., Liberati, A., Petticrew, M., Shekelle, P., Stewart, L.A. and PRISMA-P Group., Preferred reporting items for systematic review and meta-analysis protocols (PRISMA-P) 2015 statement. Systematic Reviews, 2015. 4(1): p. 1-9.

[24] Gundogan, B., Fowler, A. and Agha, R. , Assessing the compliance of systematic review articles published in leading dermatology journals with the PRISMA statement guidelines: A systematic review protocol. International Journal of Surgery Protocols, 2018. 10-12(2018): p. 1-4. 
[25] Manriquez, J., Andino-Navarrete, R., Cataldo-Cerda, K. and HarzFresno, I. , Bibliometric characteristics of systematic reviews in dermatology: A cross-sectional study through Web of Science and Scopus. Dermatologica Sinica, 2015. 33(2015): p. 154-156.

[26] Lee, Y.-H., Hsieh, Y-C and Hsu, C-N. , Adding Innovation Diffusion Theory to the Technology Acceptance Model: Supporting Employees' Intentions to use E-Learning Systems. Journal of Educational Technology and Society., 2011. 14(4): p. 124-137.
[27] Moher, D., Liberati, A., Tetzlaff, J., Altman, D.G. and Group P. , Preferred reporting items for systematic reviews and meta-analyses: the PRISMA statement. The British Medical Journal., 2009. 89(9): p. 873880.

[28] DerSimoniana, R. and Laird, N. , Meta-analysis in clinical trials revisited. . Contemporary Clinical Trials. , 2015. 45: p. 139-145.

[29] Verhagen, A. and Ferreira, M.L. , Forest Plots. Journal of Physiotherapy. , 2014. 60(3): p. 170-173. 